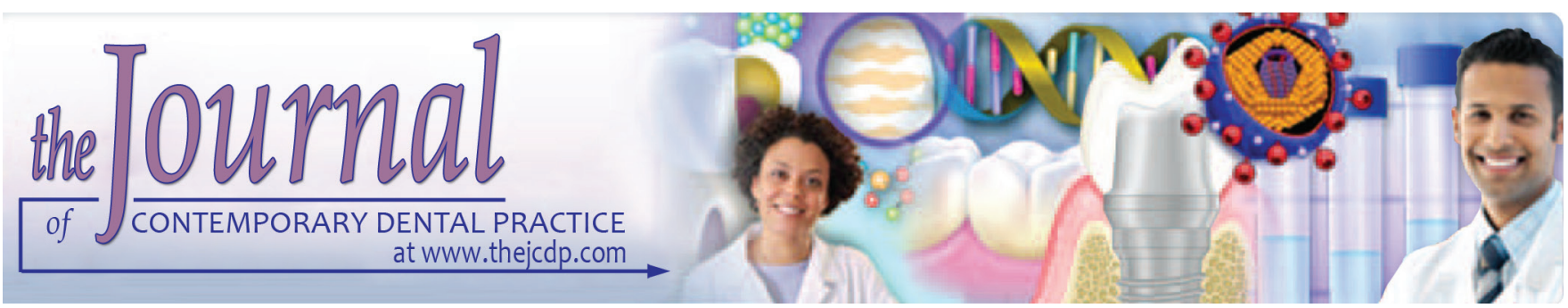

\title{
Study Model-based Evaluation of Built-in Tip, Torque, and In-out Characteristics of a Third-generation Preadjusted Edgewise Appliance
}

${ }^{1}$ Rishabh Gupta, ${ }^{2}$ Gowdara Shivaprakash, ${ }^{3}$ Mala R Manohar, ${ }^{4}$ Sonali

\begin{abstract}
Aim: The aim of the study was to evaluate the clinical effectiveness of MBT ${ }^{\mathrm{TM}}$ preadjusted edgewise appliance (PEA) in terms of achieving the optimal expression of its built-in characteristics of tip, torque, and in-out.

Materials and methods: Pretreatment and posttreatment study models of 20 subjects who received full fixed appliance treatment involving four first premolar extractions using the MBT ${ }^{\mathrm{TM}}$ appliance were measured for tip, torque, and in-out using the method described by Andrews. Treatment changes were analyzed statistically, and the posttreatment measurements were compared with the $\mathrm{MBT}^{\mathrm{TM}}$ specifications as well as Andrews' values for the above-mentioned parameters.
\end{abstract}

Results: Except for the maxillary canines and second premolars, the built-in tip of MBT ${ }^{\mathrm{TM}}$ appliance was nearly fully expressed, though there was some lack of correlation with Andrews' values. Despite the fact that the full amount of torque built into the MBT TM appliance was not expressed, torque measurements for all teeth except the maxillary second premolars and the first molars showed either no statistically significant difference or were significantly higher than Andrews' values for these teeth. In-out readings were lower than both $\mathrm{MBT}^{\mathrm{TM}}$ and Andrews' values, but the relative order of crown prominences was similar.

Conclusion and clinical significance: The MBT ${ }^{\mathrm{TM}}$ appliance is thus effective in ensuring a successful treatment result, though individual adjustments may be necessary for optimal tooth positioning at the end of the treatment, as with any preadjusted appliance.

\footnotetext{
${ }^{1}$ Department of Orthodontics and Dentofacial Orthopaedics Institute of Dental Sciences, Jammu, Jammu and Kashmir, India

${ }^{2,3}$ Department of Orthodontics and Dentofacial Orthopedics College of Dental Sciences, Davangere, Karnataka, India

${ }^{4}$ Private Practitioner, Shri Siddhivinayak Dental Clinic, Udhampur Jammu and Kashmir, India

Corresponding Author: Rishabh Gupta, Department of Orthodontics and Dentofacial Orthopaedics, Institute of Dental Sciences, Jammu, Jammu and Kashmir, India, Phone: +919419987170, e-mail: rishabh_dr@yahoo.com
}

Keywords: Crown prominence, Preadjusted edgewise appliance, Tip, Torque.

How to cite this article: Gupta R, Shivaprakash G, Manohar MR, Sonali. Study Model-based Evaluation of Built-in Tip, Torque, and In-out Characteristics of a Third-generation Preadjusted Edgewise Appliance. J Contemp Dent Pract 2018;19(1):20-29.

Source of support: Nil

Conflict of interest: None

\section{INTRODUCTION}

The development of edgewise appliances in general and PEAs, in particular, has had far-reaching effects on the practice of orthodontics. Andrews was the first one to measure tip, torque, and crown prominence of the labial surface of each tooth in previously untreated subjects with excellent occlusion. These measurements were deemed to represent the posttreatment objectives of tooth position and were used to design brackets for each tooth. This became the straight wire appliance (SWA) and was the first PEA. ${ }^{1}$

Preadjusted appliances were supposed to eliminate archwire bending, shorten treatment time, and produce more consistent treatment results. ${ }^{2}$ Clinical experience was, however, far from satisfactory and a variable amount of wire-bending was required to achieve ideal results. Proliferation of additional preadjusted appliances or "prescriptions" also gave credence to this fact, whether it was from Roth, Ricketts, Alexander, Hilgers, or others, which predominantly differed in torque of upper and lower anterior teeth. Andrews' SWA and the Roth "prescription," in particular, are often referred to as the first and the second generations of PEAs respectively.

The MBT $^{\mathrm{TM}}$ bracket system developed by McLaughlin et $\mathrm{al}^{3}$ is a third-generation PEA that introduced a range of improvements and specification changes to overcome 
the clinical shortcomings of earlier preadjusted edgewise bracket systems. Several studies on faciolingual inclination have been published, and a few statistical investigations have been performed with regard to the PEAs. ${ }^{2,4-6}$ Recently, Sondhi ${ }^{7}$ attempted to evaluate the effectiveness of appliance design on a virtual dentition and allow for an objective comparison of the effects of different torque and angulation. However, there is a lack of studies that have objectively evaluated the built-in characteristics of the $\mathrm{MBT}^{\mathrm{TM}}$ preadjusted appliance and documented its effectiveness in a clinical setting.

Our study had the following aims and objectives:

- To compare the pretreatment and posttreatment tip, torque, and in-out values in cases treated with $\mathrm{MBT}^{\mathrm{TM}}$ appliance system.

- To evaluate the effectiveness of the $\mathrm{MBT}^{\mathrm{TM}}$ appliance system in optimal expression of its built-in characteristics by comparing the posttreatment tip, torque, and in-out values to the $\mathrm{MBT}^{\mathrm{TM}}$ appliance specifications for these characteristics.

- To evaluate the effectiveness of the $\mathrm{MBT}^{\mathrm{TM}}$ appliance system in achieving an optimal occlusion by comparing the posttreatment tip, torque, and in-out values with Andrews' values.

\section{MATERIALS AND METHODS}

The sample for the study consisted of 20 subjects who received full-fixed appliance treatment using the $\mathrm{MBT}^{\mathrm{TM}}$ PEA system and attained a favorable occlusion.

All the study subjects had been treated by postgraduate students using consistent, contemporary biomechanical principles and guidance. The subjects were in the range of 16 to 30 years of age, with class I molar relation and bimaxillary dentoalveolar protrusion, an average mandibular plane angle, and treated with all four first

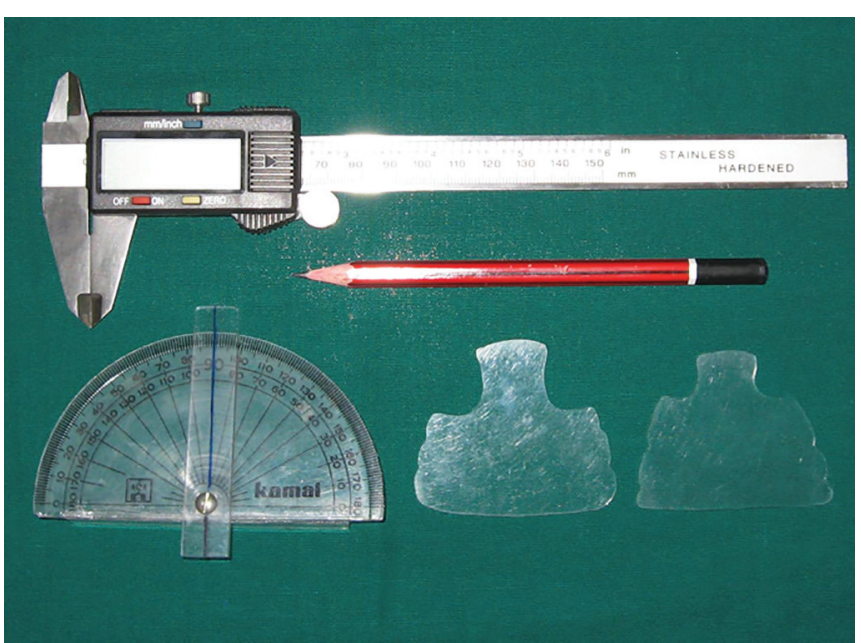

Fig. 1: Armamentarium used in the study premolar extractions. The average age of the subjects at the beginning of treatment was 17.7 years [standard deviation $(\mathrm{SD})=1.9$ years; range $16-21$ years]. The mean mandibular plane angle was $23.4^{\circ}\left(\mathrm{SD}=1.6^{\circ}\right.$; range $\left.21^{\circ}-26^{\circ}\right)$. The treatment had been done using Unitek ${ }^{\mathrm{TM}}$ Gemini metal brackets with $\mathrm{MBT}^{\mathrm{TM}}$ prescription, 0.022 slot, cuspid hooks, and $0^{\circ}$ torque cuspids (3M Unitek). A $0.019^{\prime \prime} \times 0.025^{\prime \prime}$ stainless steel was the working archwire used in all the cases.

Measurements for the purpose of our study were made on the pretreatment and posttreatment study models of study subjects with the help of a protractor with an adjustable readout arm (for measuring tip and torque) and digital sliding calipers (for measuring in-out) (Fig. 1). Two arch-shaped templates were constructed of $2 \mathrm{~mm}$-thick, rigid, flat plastic, and used to represent the occlusal plane of its respective arch (Fig. 2).

\section{Method of Measurement}

Measurements for the below-mentioned parameters were recorded using Andrews' method ${ }^{8}$ :

- Tip or crown angulation

- Torque or crown inclination

- In-out or crown prominence.

The facial axis of the clinical crown (FACC) and its midpoint, the facial axis point (FA point), were marked on each tooth of each study model (Fig. 3).

Measurements were recorded for the upper and lower central incisors, the lateral incisors, the canines, the second premolars, and the first molars as the sample consisted of cases which had their first premolars extracted during the treatment. Measurements recorded for the pretreatment models were designated as $\mathrm{T}_{1}$ and those recorded for the posttreatment models were designated as $\mathrm{T}_{2}$.

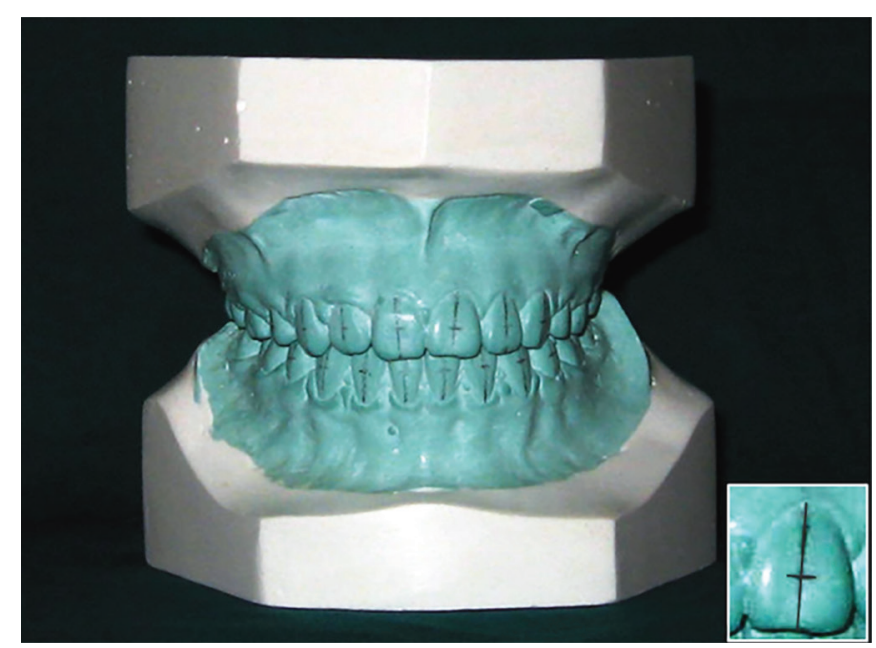

Fig. 2: The FACC (vertical line) and the FA point (junction of vertical and horizontal lines) marked on each crown 


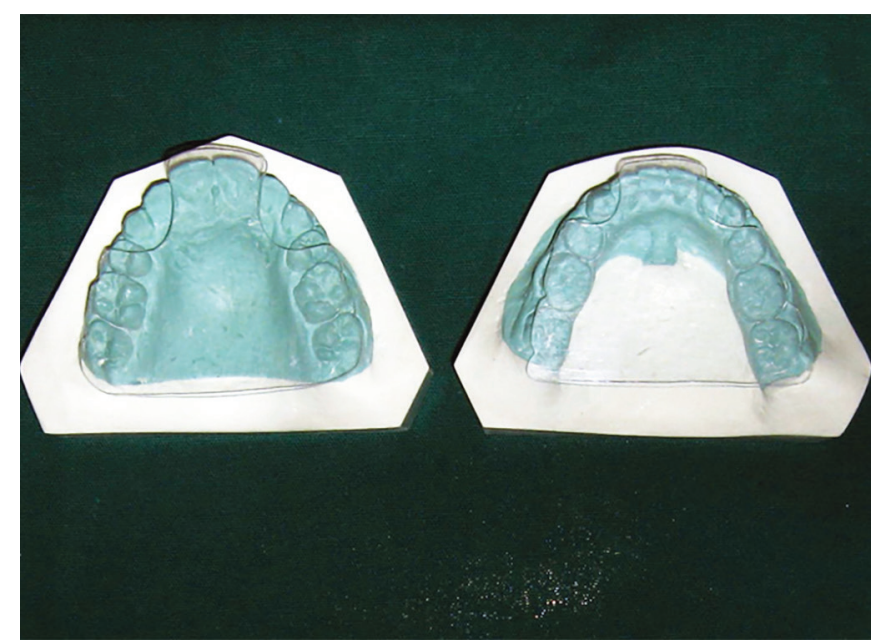

Fig. 3: Plastic occlusal templates set on the teeth

\section{Tip or Crown Angulation}

It is defined as the angle formed by the FACC (as seen from labial/buccal side) and a line drawn perpendicular to occlusal plane.

Tip is positive when the occlusal half of FACC is inclined mesial to the gingival half, and negative when it is distal.

\section{Measurement Technique}

- The arch-shaped template was positioned over the occlusal surface to represent the occlusal plane of the arch.

- The protractor was placed upright on the plastic template parallel to a line joining the contact points of the tooth being measured.

- The protractor's readout arm was placed parallel to the crown's FACC.

- The angulation of the crown was recorded where the center line of the readout arm overlapped the protractor's scale (Fig. 4).

\section{Torque or Crown Inclination}

It is defined as the angle between a line perpendicular to occlusal plane and line that is parallel and tangent to FACC at FA point.

Torque is determined from distal or mesial view. It is considered positive if occlusal half of crown or FACC is labial/buccal to its gingival portion and negative, if vice versa.

\section{Measurement Technique}

- The arch-shaped template was positioned over the occlusal surface to represent the occlusal plane of the arch.

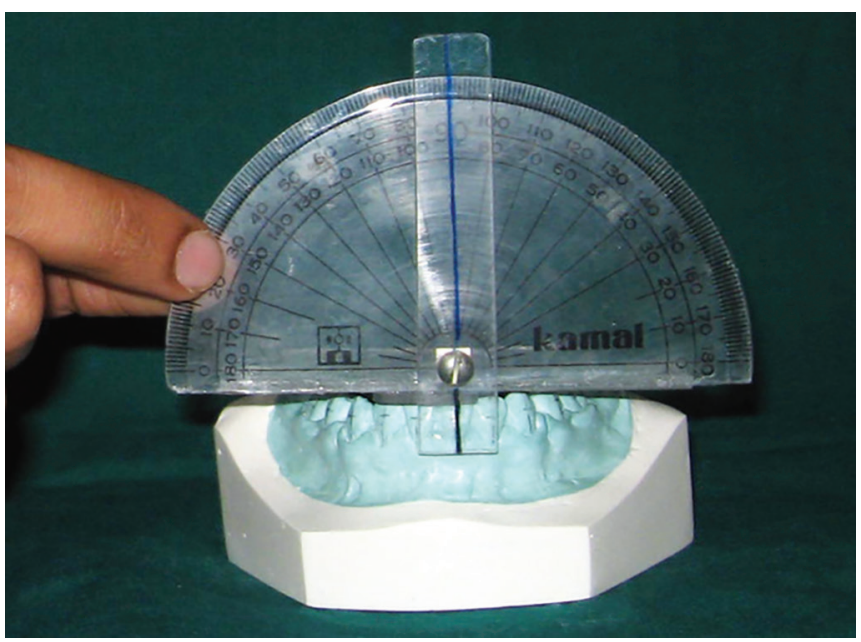

Fig. 4: Protractor positioned on the occlusal template to measure tip or crown angulation

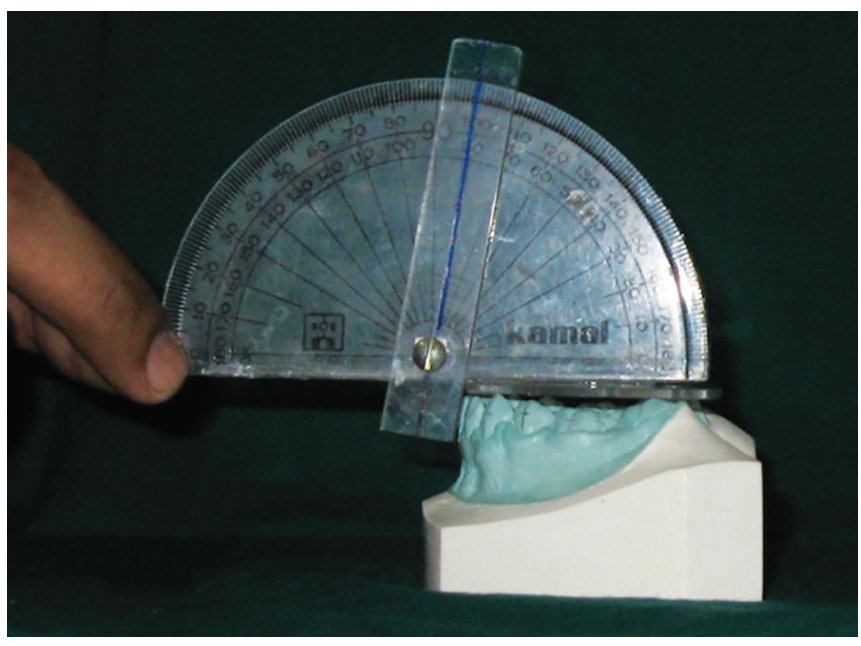

Fig. 5: Protractor positioned on the occlusal template to measure torque or crown inclination

- The protractor was placed upright on the plastic template perpendicular to a line joining the contact points of the tooth being measured.

- The protractor's readout arm was placed parallel and tangent to the tooth's FACC.

- The inclination of the crown was recorded where the center line of the readout arm overlapped the protractor's scale (Fig. 5).

\section{In-out or Crown Prominence}

It is defined as the distance from embrasure line to the crown's most prominent facial point.

\section{Measurement Technique}

On study models (duplicated), the occlusal half of each tooth crown was trimmed away. A line, designated as embrasure line, was drawn on the trimmed surfaces of the casts, connecting the most labial/buccal contact points of each tooth. The most labial/buccal portion of 


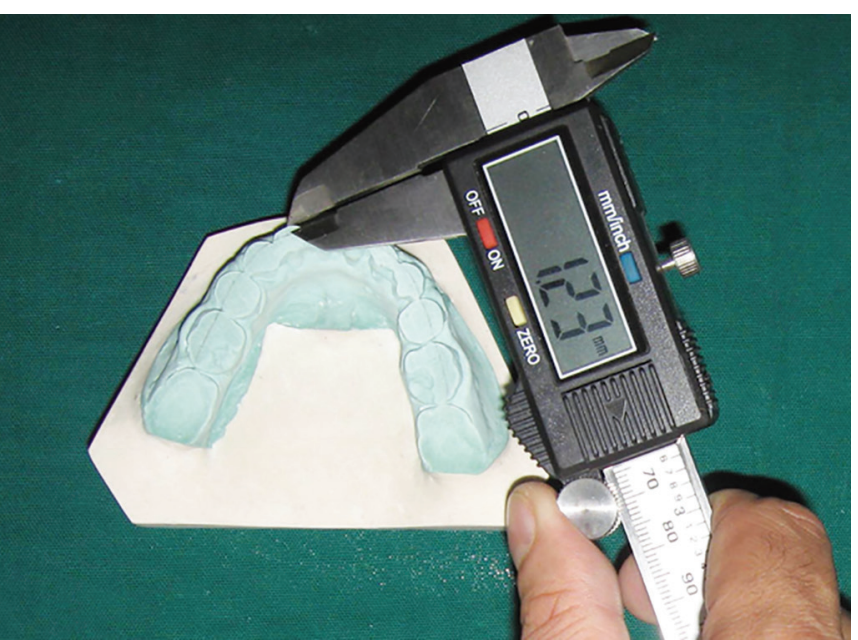

Fig. 6: Digital sliding calipers used to measure in-out or crown prominence

each tooth was measured from the embrasure line using digital sliding calipers (Fig. 6).

To test the reliability of measurements, five sets of randomly chosen study models were remeasured after 15 days. No significant difference was found between the two observations.

\section{Statistical Analysis}

The relevant statistical analyses were done using Statistical Package for the Social Sciences (version 15) software.

Results are expressed as mean \pm SD and $95 \%$ confidence intervals wherever necessary. The $95 \%$ confidence intervals were calculated as mean \pm 2 standard error (SE) and represent the population mean.

Treatment changes were analyzed using paired t-test. An unpaired t-test was used to compare with tip, torque, and in-out values from Andrews' original study. ${ }^{8}$

The $p=0.05$ or less was considered statistically significant.

\section{RESULTS}

The means, SDs, and changes in the tip, torque, and in-out measurements achieved by treatment as well as the significance values are summarized in Tables 1 to 3 . The SEs, the $95 \%$ confidence intervals as well as the comparison of tip, torque, and in-out measurements achieved posttreatment with the $\mathrm{MBT}^{\mathrm{TM}}$ appliance specifications for these parameters are summarized in Tables 4 to 6 . An

Table 1: Comparison of pretreatment vs posttreatment tip measurements

\begin{tabular}{|c|c|c|c|c|c|c|c|}
\hline & & $\begin{array}{l}\text { Pretreatment } T_{1} \\
\text { (in degrees) }\end{array}$ & $\begin{array}{l}\text { Posttreatment } T_{2} \\
\text { (in degrees) }\end{array}$ & Difference $T_{2}-T_{1}$ & & & \\
\hline Arch & Tooth & Mean $\pm S D$ & Mean $\pm S D$ & (in degrees) & $t$-value & $p$-value & Significance \\
\hline \multirow[t]{5}{*}{ Maxillary } & 1 & $3.03 \pm 5.49$ & $2.48 \pm 2.89$ & -0.55 & 0.59 & 0.56 & NS \\
\hline & 2 & $7.50 \pm 8.33$ & $9.05 \pm 5.12$ & 1.55 & 1.02 & 0.31 & NS \\
\hline & 3 & $5.98 \pm 5.55$ & $3.73 \pm 3.81$ & -2.25 & 2.54 & 0.02 & $S$ \\
\hline & 5 & $4.40 \pm 3.38$ & $3.52 \pm 4.59$ & -0.88 & 0.90 & 0.38 & NS \\
\hline & 6 & $2.18 \pm 5.24$ & $4.65 \pm 4.08$ & 2.47 & 3.10 & 0.01 & S \\
\hline \multirow[t]{5}{*}{ Mandibular } & 1 & $-0.05 \pm 0.71$ & $0.63 \pm 2.20$ & 0.68 & 0.56 & 0.58 & NS \\
\hline & 2 & $-0.02 \pm 8.22$ & $0.77 \pm 3.27$ & 0.78 & 0.56 & 0.55 & NS \\
\hline & 3 & $0.92 \pm 6.95$ & $1.70 \pm 4.41$ & 2.62 & 1.75 & 0.09 & NS \\
\hline & 5 & $4.40 \pm 5.44$ & $3.70 \pm 4.35$ & -0.70 & 0.72 & 0.47 & NS \\
\hline & 6 & $4.97 \pm 5.24$ & $3.02 \pm 5.21$ & -1.95 & 1.70 & 0.10 & NS \\
\hline
\end{tabular}

S: Significant $(p<0.05)$; NS: Not significant

Table 2: Comparison of pretreatment vs posttreatment torque measurements

\begin{tabular}{|c|c|c|c|c|c|c|c|}
\hline & & $\begin{array}{l}\text { Pretreatment } T_{1} \\
\text { (in degrees) }\end{array}$ & $\begin{array}{l}\text { Posttreatment } T_{2} \\
\text { (in degrees) }\end{array}$ & Difference $T_{2}-T_{1}$ & & & \\
\hline Arch & Tooth & Mean $\pm S D$ & Mean $\pm S D$ & (in degrees) & $t$-value & $p$-value & Significance \\
\hline \multirow[t]{5}{*}{ Maxillary } & 1 & $15.25 \pm 6.84$ & $5.78 \pm 7.99$ & -9.47 & 6.62 & $<0.001$ & S \\
\hline & 2 & $11.82 \pm 8.29$ & $6.32 \pm 6.84$ & -5.50 & 4.61 & $<0.001$ & $S$ \\
\hline & 3 & $0.13 \pm 7.59$ & $-5.45 \pm 5.27$ & -5.58 & 5.51 & $<0.001$ & S \\
\hline & 5 & $-11.52 \pm 7.21$ & $-10.92 \pm 7.00$ & 0.60 & 0.056 & 0.58 & NS \\
\hline & 6 & $-14.76 \pm 6.82$ & $-16.45 \pm 7.36$ & -1.68 & 1.54 & 0.13 & NS \\
\hline \multirow[t]{5}{*}{ Mandibular } & 1 & $12.00 \pm 5.64$ & $3.95 \pm 6.47$ & -8.05 & 11.74 & $<0.001$ & S \\
\hline & 2 & $4.30 \pm 7.37$ & $0.17 \pm 6.91$ & -4.13 & 2.12 & 0.04 & S \\
\hline & 3 & $-3.37 \pm 7.20$ & $-9.53 \pm 5.42$ & -6.17 & 6.24 & $<0.001$ & $S$ \\
\hline & 5 & $-20.12 \pm 9.67$ & $-20.92 \pm 7.76$ & -0.80 & 0.64 & 0.53 & NS \\
\hline & 6 & $-27.93 \pm 7.58$ & $-28.63 \pm 6.56$ & -0.70 & 0.69 & 0.50 & NS \\
\hline
\end{tabular}

S: Significant $(p<0.05)$; NS: Not significant 
Table 3: Comparison of pretreatment vs posttreatment in-out measurements

\begin{tabular}{|c|c|c|c|c|c|c|c|}
\hline & & $\begin{array}{l}\text { Pretreatment } T_{1} \\
\text { (in } \mathrm{mm} \text { ) }\end{array}$ & $\begin{array}{l}\text { Posttreatment } T_{2} \\
\text { (in } \mathrm{mm} \text { ) } \\
\end{array}$ & Difference $T_{2}-T_{1}$ & & & \\
\hline Arch & Tooth & Mean $\pm S D$ & Mean $\pm S D$ & (in $\mathrm{mm}$ ) & $t$-value & $p$-value & Significance \\
\hline \multirow[t]{5}{*}{ Maxillary } & 1 & $1.84 \pm 0.39$ & $1.51 \pm 0.18$ & -0.33 & 4.38 & 0.001 & $S$ \\
\hline & 2 & $1.65 \pm 0.33$ & $1.43 \pm 0.18$ & -0.22 & 3.04 & $<0.01$ & $S$ \\
\hline & 3 & $2.22 \pm 0.38$ & $1.84 \pm 0.30$ & -0.38 & 4.79 & $<0.001$ & $\mathrm{~S}$ \\
\hline & 5 & $1.60 \pm 0.41$ & $1.82 \pm 0.29$ & 0.23 & 2.11 & 0.04 & $S$ \\
\hline & 6 & $2.29 \pm 0.33$ & $2.24 \pm 0.32$ & -0.06 & 0.68 & 0.50 & NS \\
\hline \multirow[t]{5}{*}{ Mandibular } & 1 & $1.14 \pm 0.34$ & $0.99 \pm 0.24$ & -0.15 & 1.84 & 0.08 & NS \\
\hline & 2 & $1.15 \pm 0.36$ & $1.11 \pm 0.24$ & -0.04 & 0.49 & 0.63 & NS \\
\hline & 3 & $1.69 \pm 0.32$ & $1.66 \pm 0.31$ & -0.03 & 0.29 & 0.77 & NS \\
\hline & 5 & $1.97 \pm 0.29$ & $2.13 \pm 0.28$ & 0.15 & 2.48 & 0.02 & $S$ \\
\hline & 6 & $2.34 \pm 0.29$ & $2.45 \pm 0.41$ & 0.11 & 1.54 & 0.14 & NS \\
\hline
\end{tabular}

S: Significant $(p<0.05)$; NS: Not significant

Table 4: Comparison of posttreatment tip measurements with $\mathrm{MBT}^{\mathrm{TM}}$ values

\begin{tabular}{|c|c|c|c|c|c|c|c|}
\hline \multirow[b]{2}{*}{ Arch } & \multirow[b]{2}{*}{ Tooth } & \multicolumn{3}{|c|}{ Present study (in degrees) } & \multicolumn{2}{|c|}{$95 \%$ confidence interval (in degrees) } & \multirow{2}{*}{$\begin{array}{l}\text { MBT values } \\
\text { (in degrees) }\end{array}$} \\
\hline & & Mean & $S D$ & SE & Mean-2SE & Mean + 2SE & \\
\hline \multirow[t]{5}{*}{ Maxillary } & 1 & 2.48 & 2.89 & 0.53 & 1.42 & 3.54 & 4 \\
\hline & 2 & 9.05 & 5.12 & 0.93 & 7.18 & 10.92 & 8 \\
\hline & 3 & 3.73 & 3.81 & 0.70 & 2.34 & 5.12 & 8 \\
\hline & 5 & 3.52 & 4.59 & 0.84 & 1.84 & 5.20 & 0 \\
\hline & 6 & 4.65 & 4.08 & 0.74 & 3.16 & 6.14 & 5 \\
\hline \multirow[t]{5}{*}{ Mandibular } & 1 & 0.63 & 2.20 & 0.40 & -0.17 & 1.43 & 0 \\
\hline & 2 & 0.77 & 3.27 & 0.60 & -0.42 & 1.96 & 0 \\
\hline & 3 & 1.70 & 4.41 & 0.81 & 0.09 & 3.31 & 3 \\
\hline & 5 & 3.70 & 4.35 & 0.79 & 2.11 & 5.29 & 2 \\
\hline & 6 & 3.02 & 5.21 & 0.95 & 1.12 & 4.92 & 2 \\
\hline
\end{tabular}

Table 5: Comparison of posttreatment torque measurements with $\mathrm{MBT}^{\mathrm{TM}}$ values

\begin{tabular}{|c|c|c|c|c|c|c|c|}
\hline \multirow[b]{2}{*}{ Arch } & \multirow[b]{2}{*}{ Tooth } & \multicolumn{3}{|c|}{ Present study (in degrees) } & \multicolumn{2}{|c|}{$95 \%$ confidence interval (in degrees) } & \multirow{2}{*}{$\begin{array}{l}\text { MBT values } \\
\text { (in degrees) }\end{array}$} \\
\hline & & Mean & $S D$ & SE & Mean-2SE & Mean + 2SE & \\
\hline \multirow[t]{5}{*}{ Maxillary } & 1 & 5.78 & 7.99 & 1.46 & 2.86 & 8.70 & 17 \\
\hline & 2 & 6.32 & 6.84 & 1.25 & 3.82 & 8.82 & 10 \\
\hline & 3 & -5.45 & 5.27 & 0.96 & -7.37 & -3.53 & 0 \\
\hline & 5 & -10.92 & 7.00 & 1.28 & -13.48 & -8.36 & -7 \\
\hline & 6 & -16.45 & 7.36 & 1.34 & -19.14 & -13.76 & -14 \\
\hline \multirow[t]{5}{*}{ Mandibular } & 1 & 3.95 & 6.47 & 1.18 & 1.59 & 6.31 & -6 \\
\hline & 2 & 0.17 & 6.91 & 1.26 & -2.35 & 2.69 & -6 \\
\hline & 3 & -9.53 & 5.42 & 0.99 & -11.51 & -7.55 & 0 \\
\hline & 5 & -20.92 & 7.76 & 1.42 & -23.75 & -18.09 & -17 \\
\hline & 6 & -28.63 & 6.56 & 1.20 & -31.03 & -26.23 & -20 \\
\hline
\end{tabular}

unpaired $t$-test was performed to compare the observed posttreatment measurements for tip, torque, and in-out with Andrews' data for nonorthodontic normal occlusions, the results of which are summarized in Tables 7 to 9.

\section{DISCUSSION}

McLaughlin et $\mathrm{al}^{3}$ took into consideration Andrews' original findings during the development of MBT ${ }^{\mathrm{TM}}$ appliance system, in addition to research input from other sources. Andrews' six keys of occlusion also form one of the major goals for finishing the occlusion in the $\mathrm{MBT}^{\mathrm{TM}}$ system. Therefore, to facilitate comparison with the $\mathrm{MBT}^{\mathrm{TM}}$ specifications as well as Andrews' original findings, the method used in the present study was adapted from that used by Andrews in his original study. ${ }^{8}$

The relatively high SD in both pretreatment and posttreatment groups of the present study shows that there is a sizeable dispersion around the mean measurements of tip, torque, and in-out for all teeth. This is in accordance 
Study Model-based Evaluation of Built-in Tip, Torque, and In-out Characteristics of a Third-generation

Table 6: Comparison of posttreatment in-out measurements with $\mathrm{MBT}^{\mathrm{TM}}$ values

\begin{tabular}{|c|c|c|c|c|c|c|c|}
\hline \multirow[b]{2}{*}{ Arch } & \multirow[b]{2}{*}{ Tooth } & \multicolumn{3}{|c|}{ Present study (in mm) } & \multicolumn{2}{|c|}{ 95\% confidence interval (in $\mathrm{mm}$ ) } & \multirow{2}{*}{$\begin{array}{l}\text { MBT values } \\
\text { (in } \mathrm{mm} \text { ) }\end{array}$} \\
\hline & & Mean & $S D$ & SE & Mean-2SE & Mean + 2SE & \\
\hline \multirow[t]{5}{*}{ Maxillary } & 1 & 1.51 & 0.18 & 0.03 & 1.44 & 1.58 & 2.1 \\
\hline & 2 & 1.43 & 0.18 & 0.03 & 1.36 & 1.50 & 1.65 \\
\hline & 3 & 1.84 & 0.30 & 0.05 & 1.73 & 1.95 & 2.5 \\
\hline & 5 & 1.82 & 0.29 & 0.05 & 1.71 & 1.93 & 2.5 \\
\hline & 6 & 2.24 & 0.32 & 0.06 & 2.12 & 2.36 & 2.9 \\
\hline \multirow[t]{5}{*}{ Mandibular } & 1 & 0.99 & 0.24 & 0.04 & 0.90 & 1.08 & 1.2 \\
\hline & 2 & 1.11 & 0.24 & 0.04 & 1.02 & 1.20 & 1.2 \\
\hline & 3 & 1.66 & 0.31 & 0.06 & 1.55 & 1.77 & 1.9 \\
\hline & 5 & 2.13 & 0.28 & 0.05 & 2.03 & 2.23 & 2.35 \\
\hline & 6 & 2.45 & 0.41 & 0.07 & 2.30 & 2.60 & 2.5 \\
\hline
\end{tabular}

Table 7: Comparison of posttreatment tip measurements with Andrews' research values

\begin{tabular}{|c|c|c|c|c|c|c|}
\hline & & Present study (in degrees) & Andrews' study (in degrees) & & & \\
\hline Arch & Tooth & Mean $\pm S D$ & Mean $\pm S D$ & $t$-value & $p$-value & Significance \\
\hline \multirow[t]{5}{*}{ Maxillary } & 1 & $2.48 \pm 2.89$ & $3.59 \pm 1.65$ & 3.14 & $<0.01$ & S \\
\hline & 2 & $9.05 \pm 5.12$ & $8.04 \pm 2.8$ & 1.66 & 0.10 & NS \\
\hline & 3 & $3.73 \pm 3.81$ & $8.4 \pm 2.97$ & 7.85 & $<0.001$ & $S$ \\
\hline & 5 & $3.52 \pm 4.59$ & $2.82 \pm 1.52$ & 1.74 & 0.08 & NS \\
\hline & 6 & $4.65 \pm 4.08$ & $5.73 \pm 1.9$ & 2.49 & $<0.05$ & S \\
\hline \multirow[t]{5}{*}{ Mandibular } & 1 & $0.63 \pm 2.20$ & $0.53 \pm 1.29$ & 0.36 & 0.72 & NS \\
\hline & 2 & $0.77 \pm 3.27$ & $0.38 \pm 1.47$ & 1.15 & 0.25 & NS \\
\hline & 3 & $1.70 \pm 4.41$ & $2.48 \pm 3.28$ & 1.18 & 0.24 & NS \\
\hline & 5 & $3.70 \pm 4.35$ & $1.54 \pm 1.35$ & 5.82 & $<0.001$ & $S$ \\
\hline & 6 & $3.02 \pm 5.21$ & $2.03 \pm 1.14$ & 2.53 & $<0.05$ & $S$ \\
\hline
\end{tabular}

S: Significant $(p<0.05)$; NS: Not significant

Table 8: Comparison of posttreatment torque measurements with Andrews' research values

\begin{tabular}{|c|c|c|c|c|c|c|}
\hline & & Present study (in degrees) & Andrews' study (in degrees) & & & \\
\hline Arch & Tooth & Mean $\pm S D$ & Mean $\pm S D$ & t-value & $p$-value & Significance \\
\hline \multirow[t]{5}{*}{ Maxillary } & 1 & $5.78 \pm 7.99$ & $6.11 \pm 3.97$ & 0.37 & 0.71 & NS \\
\hline & 2 & $6.32 \pm 6.84$ & $4.42 \pm 4.38$ & 2.08 & $<0.05$ & S \\
\hline & 3 & $-5.45 \pm 5.27$ & $-7.25 \pm 4.21$ & 2.14 & $<0.05$ & S \\
\hline & 5 & $-10.92 \pm 7.00$ & $-8.78 \pm 4.13$ & 2.44 & $<0.05$ & S \\
\hline & 6 & $-16.45 \pm 7.36$ & $-11.53 \pm 3.91$ & 5.75 & $<0.001$ & $S$ \\
\hline \multirow[t]{5}{*}{ Mandibular } & 1 & $3.95 \pm 6.47$ & $-1.71 \pm 5.79$ & 4.98 & $<0.001$ & S \\
\hline & 2 & $0.17 \pm 6.91$ & $-3.24 \pm 5.37$ & 3.17 & $<0.01$ & S \\
\hline & 3 & $-9.53 \pm 5.42$ & $-12.73 \pm 4.65$ & 3.49 & $<0.01$ & S \\
\hline & 5 & $-20.92 \pm 7.76$ & $-23.63 \pm 5.58$ & 2.39 & $<0.05$ & S \\
\hline & 6 & $-28.63 \pm 6.56$ & $-30.67 \pm 5.9$ & 1.76 & 0.08 & NS \\
\hline
\end{tabular}

S: Significant $(p<0.05)$; NS: Not significant

Table 9: Comparison of posttreatment in-out measurements with Andrews' research values

\begin{tabular}{|c|c|c|c|c|c|c|}
\hline & & Present study (in $\mathrm{mm}$ ) & Andrews' study (in $\mathrm{mm}$ ) & & & \\
\hline Arch & Tooth & Mean $\pm S D$ & Mean $\pm S D$ & $t$-value & $p$-value & Significance \\
\hline \multirow[t]{5}{*}{ Maxillary } & 1 & $1.51 \pm 0.18$ & $2.01 \pm 0.32$ & 8.38 & $<0.001$ & $\mathrm{~S}$ \\
\hline & 2 & $1.43 \pm 0.18$ & $1.84 \pm 0.30$ & 7.32 & $<0.001$ & S \\
\hline & 3 & $1.84 \pm 0.30$ & $2.67 \pm 0.39$ & 11.24 & $<0.001$ & $S$ \\
\hline & 5 & $1.82 \pm 0.29$ & $2.48 \pm 0.36$ & 9.65 & $<0.001$ & S \\
\hline & 6 & $2.24 \pm 0.32$ & $2.88 \pm 0.40$ & 8.43 & $<0.001$ & $S$ \\
\hline \multirow[t]{5}{*}{ Mandibular } & 1 & $0.99 \pm 0.24$ & $1.59 \pm 0.27$ & 11.61 & $<0.001$ & $S$ \\
\hline & 2 & $1.11 \pm 0.24$ & $1.64 \pm 0.30$ & 9.31 & $<0.001$ & $S$ \\
\hline & 3 & $1.66 \pm 0.31$ & $2.37 \pm 0.40$ & 9.37 & $<0.001$ & $S$ \\
\hline & 5 & $2.13 \pm 0.28$ & $2.60 \pm 0.34$ & 7.27 & $<0.001$ & $S$ \\
\hline & 6 & $2.45 \pm 0.41$ & $3.02 \pm 0.40$ & 7.34 & $<0.001$ & $\mathrm{~S}$ \\
\hline
\end{tabular}

S: Significant $(p<0.05)$; NS: Not significant 
with previous studies. ${ }^{2,5,8}$ Although the sample size of our study was lesser than that of Andrews' study, the SDs were similar. ${ }^{8}$

\section{Tip or Crown Angulation}

Tip is Andrews' second key to occlusion. In normal occlusion, this is seen as a distal inclination of the gingival portion of each crown, i.e., positive tip. This was the finding in our study where all teeth at the posttreatment stage showed a positive tip (Table 1). ${ }^{8}$

According to the proponents of the $\mathrm{MBT}^{\mathrm{TM}}$ system, using light continuous force mechanics, tip is well controlled and the built-in specifications are fully expressed clinically. ${ }^{3}$ The present study's posttreatment tip values point to similar findings:

- In the maxillary arch, the $\mathrm{MBT}^{\mathrm{TM}}$ tip values for only lateral incisor $\left(8^{\circ}\right)$ and first molar $\left(5^{\circ}\right)$ were within the $95 \%$ confidence intervals for posttreatment tip measurements of these teeth, though $\mathrm{MBT}^{\mathrm{TM}}$ tip of $4^{\circ}$ for maxillary central incisors was only slightly greater than the upper limit of $95 \%$ confidence limits for this tooth. In contrast, $\mathrm{MBT}^{\mathrm{TM}}$ specifications for maxillary canines $\left(8^{\circ}\right)$ and second premolars $\left(0^{\circ}\right)$ were well out of the $95 \%$ confidence limits for these teeth (Table 4).

- In the mandibular arch, $\mathrm{MBT}^{\mathrm{TM}}$ tip specifications for central incisors $\left(0^{\circ}\right)$, lateral incisors $\left(0^{\circ}\right)$, canines $\left(3^{\circ}\right)$, and the first molars $\left(2^{\circ}\right)$ fall between the $95 \%$ confidence intervals of the posttreatment measurements in the present study. $\mathrm{MBT}^{\mathrm{TM}}$ tip of $2^{\circ}$ for mandibular second premolars is only slightly less than the lower limit of $95 \%$ confidence limits for this tooth (Table 4).

Thus, except for maxillary canines and second premolars, tip specification of $\mathrm{MBT}^{\mathrm{TM}}$ appliance system was reasonably well expressed.

There was, however, some lack of correlation when posttreatment tip measurements were compared statistically with Andrews' original findings. ${ }^{8}$

- In the maxillary arch, tip measurements for lateral incisors and second premolars showed no statistically significant difference from Andrews' tip measurements, though tip measurements for maxillary central incisors, canines, and first molars were significantly different (Table 7).

- In the mandibular arch, tip measurements for central incisors, lateral incisors, and canines showed no significant difference from Andrews' tip values, though tip measurements for second premolars and first molars were significantly different (Table 7).

Problems with expression of tip may arise due to a number of factors. Brackets not bonded parallel to the long axis of the tooth, irregular labial/buccal crown surface, crown-root angulations, and abnormal tooth shapes may result in tip variations., ${ }^{9,10}$ Rapid space closure can also lead to loss of tip control, which may produce unwanted movement of canines, premolars, and molars. ${ }^{11}$ In addition, teeth adjacent to extraction spaces may tip excessively while closing the spaces with lessthan-efficient subsequent uprighting, which can explain for reduced tip of the maxillary canines.

\section{Torque or Crown Inclination}

Torque is Andrews' third "key to occlusion", which in normal occlusion is seen as upper incisors having a positive inclination, lower incisors with slightly negative inclination, and a progressively greater "minus" crown inclination from maxillary as well as mandibular canines to molars. ${ }^{8}$ This was followed in this study's posttreatment occlusions except for mandibular central and lateral incisors, which had a positive crown inclination posttreatment.

Our study sample consisted of cases with bimaxillary dentoalveolar protrusion whose treatment involved four first premolar extractions. Posttreatment occlusion showed a considerable reduction in torque of upper as well as lower anteriors, which was statistically significant, indicating an expected progress toward the treatment goals (Table 2).

MBT $^{\mathrm{TM}}$ torque values ${ }^{4}$ for only maxillary first molars $\left(-14^{\circ}\right)$ fall between the $95 \%$ confidence intervals of the posttreatment measurements in the present study, i.e., for all other teeth, the MBT ${ }^{\mathrm{TM}}$ values were more than the upper limit of the $95 \%$ confidence intervals of the posttreatment measurements in the present study except for the mandibular central and lateral incisors, for which the $\mathrm{MBT}^{\mathrm{TM}}$ values were less than the lower limit of the $95 \%$ confidence intervals of the posttreatment torque measurements (Table 5).

Problems with full expression of torque values built into the appliance may be due to two mechanical reasons. First, the area of where torque is applied is small and depends on the twist effect of a comparatively small wire, in contrast to the size of the tooth. Second, in sliding mechanics, we use $0.019^{\prime \prime} \times 0.025^{\prime \prime}$ steel wires in 0.022 slot because a full-thickness wire tends to increase friction. The 0.019 " $\times 0.025$ " steel wires have a "slop" or "play" of approximately $10^{\circ}$, depending on manufacturing discrepancies and the amount of wire edge "rounding" or "radiusing. ${ }^{3}$ With full-sized archwires also, considerable play is evident during torquing. ${ }^{10}$ Roth $^{11}$ and Swain ${ }^{12}$ have recommended overcorrection to compensate for the above. 
Other factors may also contribute to the variations seen in torque expression:

- Errors in bracket placement, particularly in teeth with marked labial/buccal curvature.

- Thurow ${ }^{13}$ showed that altering the vertical position of the bracket leads to alterations in torque expression.

- Meyers and Nelson ${ }^{14}$ have stated that lower first premolars have the most pronounced occlusogingival curvature among all teeth and that displacing the bracket by $3 \mathrm{~mm}$ can result in up to $15^{\circ}$ alteration in the torque applied.

- Germane et $\mathrm{al}^{15}$ described that vertical displacement of bracket by $1 \mathrm{~mm}$ can result in up to $10^{\circ}$ alteration in the torque applied.

- Thickness of the bracket-bonding adhesive beneath brackets and tubes is another important factor causing errors torque expression. ${ }^{2}$

- Labial/buccal contours of teeth have also not been found to be identical between patients, which tends to affect torque expression. . $^{16,17}$

Of particular clinical importance is the posttreatment torque measurement for maxillary central incisors. Torque of the upper incisors is an important factor in establishing the smile line, proper anterior guidance, and class I relationship of the teeth because anterior teeth with deficient torque tend to prevent the distal movement of the anterior maxillary segment. ${ }^{18}$ The posttreatment torque measurement for this tooth $\left(5.78^{\circ}\right)$ also correlates well with the Andrews' torque value of $6.11^{\circ}$ from which it shows no statistically significant difference (Table 8). Thus, maxillary central incisors showed posttreatment torque similar to Andrews' values for this tooth in nonorthodontic normal occlusion and showed insignificant torque loss during treatment. This might be attributed to the effectiveness of the appliance, but the pretreatment high torque measurements of these teeth might as well be responsible for adequate posttreatment torque.

High pretreatment torque measurements might also be responsible for positive posttreatment torque of mandibular incisors (Table 8). Increase in the labiolingual inclination of mandibular incisors may also occur during leveling of the curve of Spee and elimination of lower incisor crowding. ${ }^{19}$ The labiolingual inclination of lower incisors has been found to decrease as the mandibular plane angle increases and vice vers $a,{ }^{20}$ which demonstrates that different normals need to be used, depending on the underlying skeletal patterns. ${ }^{3}$ The present study included only the subjects with an average mandibular plane angle to eliminate the effect of this variable.

Despite the fact that full amount of torque built into the MBT ${ }^{\mathrm{TM}}$ appliance was not expressed, torque measurements for all teeth except maxillary second premolars and first molars showed either no statistically significant difference or were significantly higher than Andrews' values for these teeth. While designing the MBT ${ }^{\mathrm{TM}}$ bracket system, extra torque was incorporated in the incisor and molar regions so as to place them in the desired positions with minimum wire bending as it was known that edgewise brackets are relatively inefficient in the expression of torque. ${ }^{3}$ The $\mathrm{MBT}^{\mathrm{TM}}$ appliance thus, assisted the treatment mechanics for maintaining the torque for all the teeth except upper second premolars and first molars.

\section{In-out or Crown Prominence}

To avoid first-order archwire bends, Andrews suggested alteration in thickness of the bracket base. ${ }^{8}$ The least prominent teeth in the arch (upper lateral incisor) were provided the thickest base, and the most prominent teeth in the arch (the molars) were provided with the thinnest bases. ${ }^{6}$

In-out values for both maxillary and mandibular teeth show a variation from $\mathrm{MBT}^{\mathrm{TM}}$ specifications (Table 6). This may be due to improper vertical placement of brackets as well as improper thickness of the adhesive beneath the bracket bases. ${ }^{3,10,15}$ Variation of facial crown contour may also be a contributing factor. ${ }^{16,17}$

All teeth in this study had mean in-out values that were significantly lower than Andrews' original findings, but the relative crown prominence follows a pattern similar to that seen in Andrews' study, a point of considerable importance.

- In the maxillary arch, Andrews' original findings show that in-out was greatest for the first molars at $2.88 \mathrm{~mm}$. These measurements were similar to the present inout measurement of first molars at $2.24 \mathrm{~mm}$. The next most-prominent tooth in the maxillary arch was the canine at $2.67 \mathrm{~mm}$ in Andrews' study and $1.84 \mathrm{~mm}$ in the present study. The second premolars were $2.48 \mathrm{~mm}$ from the embrasure line in Andrews' study and $1.82 \mathrm{~mm}$ in the present study. The central incisor was the next most-prominent tooth at $2.01 \mathrm{~mm}$ in Andrews' study; it was $1.51 \mathrm{~mm}$ in the present study. The lateral incisor was the least prominent tooth at $1.84 \mathrm{~mm}$ in Andrews' study; it was $1.43 \mathrm{~mm}$ in the present study (Table 9).

- The measurements for mandibular arch were fairly similar to that of the maxillary arch. The most prominent teeth in the mandibular arch were the first molars at 3.02 in Andrews' study and $2.45 \mathrm{~mm}$ in the present study. There is a progressive decrease in crown prominence as we move anteriorly; the second premolars were at $2.60 \mathrm{~mm}$ in Andrews' study and $2.13 \mathrm{~mm}$ in the present study. The canine was $2.37 \mathrm{~mm}$ from the embrasure line in Andrews' study and $1.66 \mathrm{~mm}$ in the present study. The central and lateral incisors 
were undoubtedly the least prominent teeth at 1.59 and $1.64 \mathrm{~mm}$ in Andrews' study and $0.99 \mathrm{~mm}$ and $1.11 \mathrm{~mm}$ respectively, in the present study (Table 9).

Therefore, the apparent lack of correlation of present study in-out measurements with MBT $^{\mathrm{TM}}$ in-out should be seen in the light of the following two observations:

1. Although all the present study readings are significantly lower than Andrews' original findings, the same pattern has been exhibited with regard to maximum and minimum relative crown prominences. ${ }^{6,8}$

2. Previous studies by Andrews, ${ }^{8}$ Currim and Wadkar, 6 Sebata, and Watanabe ${ }^{3}$ have also found the in-out measurements to be quite satisfactory. In fact, McLaughlin et $\mathrm{al}^{3}$ stated that no alterations were required in Andrews' original untreated normal measurements of in-out compensations as it is $100 \%$ fully expressed due to the snug fit of arch within the bracket slot.

All factors considered, preadjusted systems have provided great benefits to orthodontists in all stages of treatment, the $\mathrm{MBT}^{\mathrm{TM}}$ appliance system being a valuable improvement over the earlier systems. The significant dispersion seen in all the measurements in our study points out that individual variations should be kept in mind when treating patients. Clearly, one preadjusted appliance prescription cannot fit all the patients. While selecting a bracket prescription, biologic differences in tooth posture and structure, maxillary/mandibular relationships, ${ }^{20}$ mechanical shortcomings of the edgewise appliances, ${ }^{18}$ and the variations in different biomechanical principles ${ }^{2}$ should be taken into consideration. It is important to position the brackets as accurately as possible and in case of major deviations to perform the bracket positioning indirectly. ${ }^{9,10,15,17,20}$ The rectangular steel $0.019^{\prime \prime} \times 0.025^{\prime \prime}$ working wires may be tied with 0.010 -inch ligature wires using ligature-tying pliers or hemostats and ligature directors to provide a more positive archwire engagement so that a better expression of the features built-in to the bracket system can be achieved. ${ }^{3}$ During the treatment, extreme care should be taken with the mechanics, especially avoiding overly rapid space closure, which can lead to loss of control of tip, torque, and rotation. ${ }^{3,10}$ Occasionally, $0.021^{\prime \prime} \times 0.025^{\prime \prime}$ stainless steel wires may be considered in the later stages of treatment to obtain full expression of the bracket system. ${ }^{3}$ To obtain an optimally finished occlusion, alterations in the archwire, with builtin overcorrection are often required.

\section{CONCLUSION}

The present study led to the following conclusions regarding the effectiveness of the MBT ${ }^{\mathrm{TM}}$ appliance system in terms of expression of its built-in characteristics:

- Tip was reasonably well expressed except for the maxillary canines and second premolars.
- Torque was not fully expressed, though the posttreatment torque measurements for almost all the teeth were similar or even more positive than those for nonorthodontic normal occlusions of Andrews' study, indicating a limited loss of torque during the treatment.

- In-out was also not expressed fully, but the relative order of crown prominence was similar to both $\mathrm{MBT}^{\mathrm{TM}}$ values and in Andrews' nonorthodontic normal occlusions in both maxillary and mandibular arches. The $\mathrm{MBT}^{\mathrm{TM}}$ appliance is thus effective in ensuring a successful treatment result.

\section{Clinical Significance}

A considerable dispersion around the mean measurements was found for all the parameters in all teeth. This indicates that it may be unreasonable to anticipate that any SWA without individual adjustments can lead to an optimal tooth positioning at the end of the treatment.

\section{REFERENCES}

1. Creekmore TD, Kunik RL. Straight wire: the next generation. Am J Orthod Dentofacial Orthop 1993 Jul;104(1):8-20.

2. Uğur T, Yukay F. Normal faciolingual inclinations of tooth crowns compared with treatment groups of standard and pretorqued brackets. Am J Orthod Dentofacial Orthop 1997 Jul;112(1):50-57.

3. McLaughlin, RP.; Bennett, JC.; Trevisi, HJ. Systemized orthodontic treatment mechanics. St Louis (MO): CV Mosby Co; 2001. pp. 27-54.

4. Dellinger EL. A scientific assessment of the straight-wire appliance. Am J Orthod 1978 Mar;73(3):290-299.

5. Vardimon AD, Lambertz W. Statistical evaluation of torque angles in reference to straight-wire appliance (SWA) theories. Am J Orthod 1986 Jan;89(1):56-66.

6. Currim S, Wadkar PV. Objective assessment of occlusal and coronal characteristics of untreated normals: a measurement study. Am J Orthod Dentofacial Orthop 2004 May;125(5):582-588.

7. Sondhi, A. The impact of bracket selection and bracket placement on expressed tooth movement and finishing details. In: Nanda R, Kapila S, editors. Current therapy in orthodontics. St. Louis (MO): Mosby; 2010. pp. 68-77.

8. Andrews, LF. Straight wire: the concept and appliance. San Diego (CA): K-W Publications; 1989. pp. 13-33.

9. McLaughlin RP, Bennett JC. Finishing and detailing with a preadjusted appliance system. J Clin Orthod 1991 Apr;25(4): 251-264.

10. Bennett JC, McLaughlin RP. Controlled space closure with a preadjusted appliance system. J Clin Orthod 1990 Apr;24(4):251-260.

11. Roth, RH. Treatment mechanics for the straight-wire appliance. In: Graber LW, Swain BF, editors. Orthodontics, current principles and techniques. St Louis (MO): CV Mosby; 1985. pp. 665-716.

12. Swain, BF. Straight-wire design strategies: five year evaluation of the Roth modification of the Andrews straight-wire appliance. In: Graber LW, editor. Orthodontics; state of the art, essence of the science. St Louis (MO): CV Mosby; 1986. pp. 279-298. 
13. Thurow, RC. Edgewise orthodontics. 4th ed. St Louis (MO): CV Mosby Co; 1982. pp. 196-218.

14. Meyer M, Nelson G. Preadjusted edgewise appliances: theory and practice. Am J Orthod 1978 May;73(5):485-498.

15. Germane N, Bentley BE Jr, Isaacson RJ. Three biologic variables modifying faciolingual tooth angulation by straightwire appliances. Am J Orthod Dentofacial Orthop 1989 Oct; 96(4):312-319.

16. Miethke RR, Melsen B. Effect of variation in tooth morphology and bracket position on first and third order correction with preadjusted appliances. Am J Orthod Dentofacial Orthop 1999 Sep;116(3):329-335.
17. Gioka C, Eliades T. Materials-induced variation in the torque expression of preadjusted appliances. Am J Orthod Dentofacial Orthop 2004 Mar;125(3):323-328.

18. Thicket E, Taylor NG, Hodge T. Choosing a pre-adjusted orthodontic appliance prescription for anterior teeth. J Orthod 2007 Jun;34(2):95-100.

19. Ross VA, Isaacson RJ, Germane N, Rubenstein LK. Influence of vertical growth pattern on faciolingual inclinations and treatment mechanics. Am J Orthod Dentofacial Orthop 1990 Nov;98(5):422-429.

20. McLaughlin RP, Bennett JC. Bracket placement with the preadjusted appliance. J Clin Orthod 1995 May;29(5):302-311. 